\title{
Research on Multidisciplinary Optimization Design of Bridge Crane
}

\author{
Tong Yifei, ${ }^{1}$ Ye Wei, ${ }^{1}$ Yang Zhen, ${ }^{1}$ Li Dongbo, ${ }^{1}$ and Li Xiangdong ${ }^{2}$ \\ ${ }^{1}$ Nanjing University of Science and Technology, School of Mechanical Engineering 402, 210094 Nanjing, China \\ ${ }^{2}$ Jiangsu Province Special Equipment Safety Supervision Inspection Institute, LongJiang Building, 107 Caochangmen Street, \\ Jiangsu Province, 210000 Nanjing, China
}

Correspondence should be addressed to Li Dongbo; db_tyf@yahoo.cn

Received 17 February 2013; Accepted 7 May 2013

Academic Editor: C. Wu

Copyright (C) 2013 Tong Yifei et al. This is an open access article distributed under the Creative Commons Attribution License, which permits unrestricted use, distribution, and reproduction in any medium, provided the original work is properly cited.

\begin{abstract}
Bridge crane is one of the most widely used cranes in our country, which is indispensable equipment for material conveying in the modern production. In this paper, the framework of multidisciplinary optimization for bridge crane is proposed. The presented research on crane multidisciplinary design technology for energy saving includes three levels, respectively: metal structures level, transmission design level, and electrical system design level. The shape optimal mathematical model of the crane is established for shape optimization design of metal structure level as well as size optimal mathematical model and topology optimal mathematical model of crane for topology optimization design of metal structure level is established. Finally, system-level multidisciplinary energy-saving optimization design of bridge crane is further carried out with energy-saving transmission design results feedback to energy-saving optimization design of metal structure. The optimization results show that structural optimization design can reduce total mass of crane greatly by using the finite element analysis and multidisciplinary optimization technology premised on the design requirements of cranes such as stiffness and strength; thus, energy-saving design can be achieved.
\end{abstract}

\section{Introduction}

Empirical design is often used for the structure design of bridge crane, which determines the design parameters of bridge crane and furthermore improves the performance. The traditional design method cannot work out accurate performance data resulting in the safe coefficient of crane over the design requirements greatly, which leads to the waste of materials and energy consumption, and so forth [1].

At present, a simplified structure to reduce the weight and lightweight design-based heuristic algorithm is usually adopted to achieve energy saving, most of which focus on single structural design improvement. With the rapid development of finite element analysis (FEA) technique $[2,3]$, the traditional design method is gradually replaced by finite element analysis and design. There is quite a lot of finite element analysis software such as ANSYS, ABAQUS, and HyperWorks $[4,5]$. However, purely from structural design, to reduce the weight of the crane has been very limited, and blindly to reduce the weight would be a security risk.
On the other hand, crane is a complex system composed of many subsystems, among which there exist weak or strong coupling relationships. Thus, crane energy-saving design is a multidisciplinary coupling engineering problem involving structural design, mechanical transmission, and electrical control, which is not a simple superposition and permutations of various disciplines design. Therefore, it is of urgent need from multidisciplinary point of view of structure, mechanical transmission, and electrical control to study the system-level energy-saving design of crane.

The present work was carried out in order to obtain simulation data of the bridge crane. In the next section, the framework of multidisciplinary optimization design is proposed. In Section 3, FE model of double girder crane is developed using commercial program HyperWorks, and the loading and the results of finite element analysis are given and discussed. Topology optimization and size optimization are further carried out, and the results of metal structural optimization are analyzed. In Section 4, systemlevel multidisciplinary energy-saving optimization design 
of bridge crane is further carried out with transmissionlevel design results feedback to energy-saving optimization design of metal structure. Finally, research conclusions are summarized.

\section{Multidisciplinary Optimization Design Framework for Bridge Crane Energy Saving}

The presented research on crane multidisciplinary design technology for energy saving includes three levels, respectively: energy-saving design of metal structures, energy-saving transmission design, and energy-saving electrical system design. Energy-saving design of metal structure involves structural lightweight design and arch curve design of beam; energy-saving transmission system design involves dynamic loading, transmission efficiency, and components lightweight, and energy-saving electric system design involves power loss.

In addition, optimal design of lifting findings dynamic loading and components lightweight are feedback to structure lightweight design for further design optimization. Also, arch curve can reduce climbing energy consumption, thereby reducing motor power losses. The arch curve optimization results need feedback for electrical energy saving. The multidisciplinary optimization design can be illustrated as shown in Figure 1.

\section{Energy-Saving Optimization Design of Metal Structure Level of Bridge Crane}

3.1. Development of FE Model of Double Girder Crane. Take a bridge crane used in a practical project as the research object, which is a $50 \mathrm{t}-31.5 \mathrm{~m}$ double girder crane whose material parameter and usage are as follows:

(i) material: ordinary carbon steel Q235;

(ii) length of the crane $(l): 31.5 \mathrm{~m}$;

(iii) maximum lifting height: $12 \mathrm{~m}$;

(iv) hoisting speed: $7.8 \mathrm{~m} / \mathrm{min}$;

(v) moving speed of the car: $38.5 \mathrm{~m} / \mathrm{min}$;

(vi) moving speed of the cart: $87.3 \mathrm{~m} / \mathrm{min}$.

And according to the GBT 3811-2008 "crane design standard," the working level of car is M5, and the working level of cart is M6 [6].

3.2. Geometric Modeling of Double Girder Crane. According to the engineering drawing, geometric model of the bridge crane is established by $\mathrm{PRO} / \mathrm{E}$, whose structure components include the up and down plates of end girders, the side plates of end girders, up and down plates of main girders, the side plates of main girders, multiple belly boards, feet frame, and various connection boards. The simplified geometric model is shown as Figure 2.

3.3. Model Processing. Import the geometric model of bridge crane into HyperMesh and clear it. Owing to that each plate is thin, partition the plates with shell elements for finite element simulation analysis. The shell elements should be created on the middle surface of the geometry. A group of middle surfaces should be constructed by using "midsurface" panel. The imported model contains some connectivity error or some other defects, so the operations as follows should be carried out after importing file model.

(1) Delete the unsheared surfaces.

(2) Fill the gaps (repair the missed surfaces).

(3) Set the tolerance values of geometric cleaning.

(4) Combine the red free edges with "equivalence."

(5) Delete the repeated surfaces.

3.4. Mesh Partitioning of Double Girder Crane. Welds connections between each board are taken place of the rigid connections, and mesh elements are created on extraction midsurface [7]. The calculation capacity and calculation efficiency must be considered when mesh partitioning. The finer the elements meshed are, the more accordant the partitioned model is with the actual condition, while computing time and memory usage will be increased largely. After taking all the above factors into account synthetically, set the element size as $50 \mathrm{~mm} \times 50 \mathrm{~mm}$ for finite element analysis. The spot welds are used to simulate the connections between the end and main girders [8].

Due to that the bridge crane structure is symmetrical, take half of the model as research object in order to reduce the computing time and memory usage. The FE model of bridge cranes is shown in Figure 3.

3.5. Loading and Static Analysis. Both end girders and main girders are processed as simply supported beams [9-11]. Loading is illustrated as in Figure 4.

Constraint loadings of the crane are described as follows:

the movement in $x, y, z$ directions and the rotation in $z$ direction of position 1 are restrained;

the movement in $y, z$ direction and the rotation in $z$ direction of position 4 are restrained;

the movement in $z$ direction and the rotation in $x, y$ direction of positions 2, 3 are restrained because of the symmetry.

The loadings on both of the main girders are as follows:

(i) rated hoisting loading: $P_{\mathrm{Q}}=50 \mathrm{t}$;

(ii) the car mass is $15.765 \mathrm{t}$;

(iii) self-vibration load factor $\Phi_{1}=1.1$;

(iv) lifting dynamic load factor $\Phi_{2}=1.14$;

(v) horizontal inertial force of crane as volume force: acceleration is $0.32 \mathrm{~m} / \mathrm{s}^{2}$;

(vi) cart gravity as volume force.

L0, L1, L2, L3, and L4 denote the loadings on different positions of one main girder, respectively, called five work 


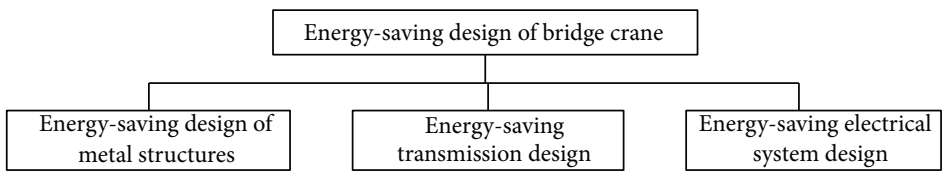

(a) Overall framework of multidisciplinary energy-saving design

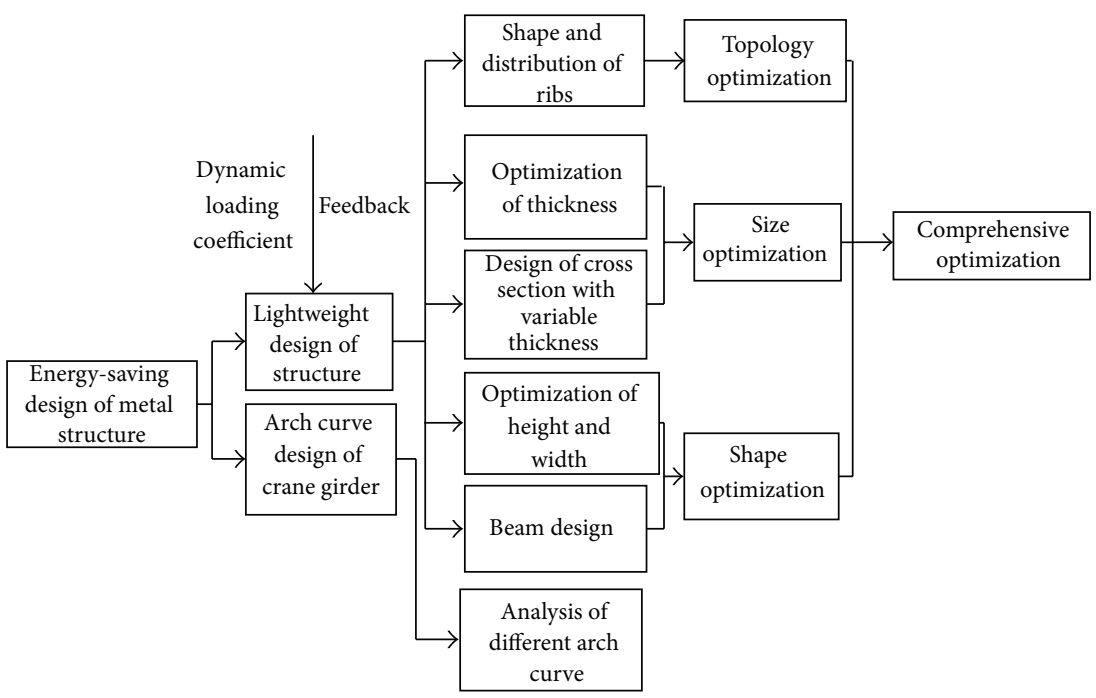

(b) Energy-saving design of metal structure level

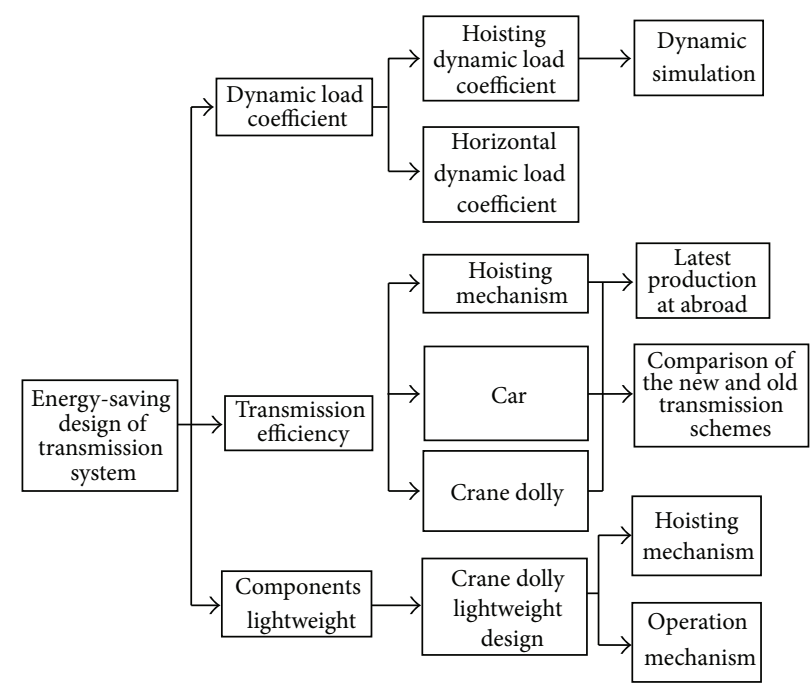

(c) Energy-saving design of transmission design level

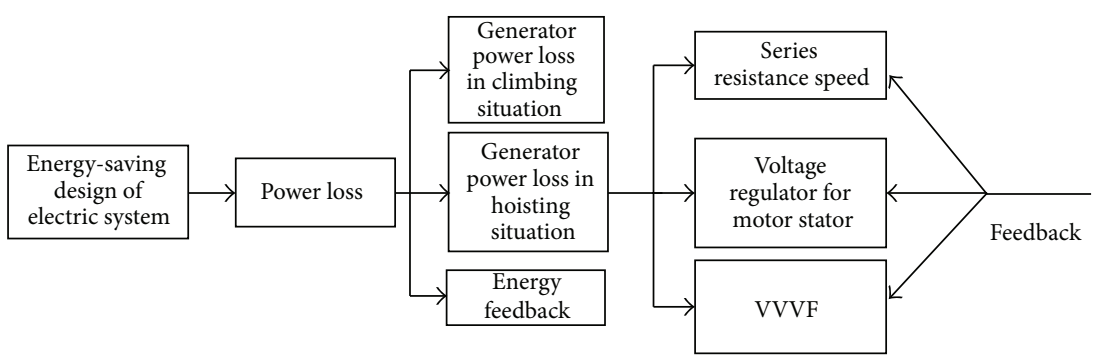

(d) Energy-saving design of electrical system design level

FIGURE 1: Multidisciplinary optimization design framework for energy saving. 
TABLE 1: Five work conditions description.

\begin{tabular}{|c|c|c|c|c|c|c|c|}
\hline $\begin{array}{l}\text { Work } \\
\text { conditions }\end{array}$ & $\begin{array}{l}\text { Cart gravity } \\
\left(\mathrm{m} / \mathrm{s}^{2}\right)\end{array}$ & $\begin{array}{c}\text { Car mass } \\
(\mathrm{t})\end{array}$ & $\begin{array}{l}\text { Self-vibration } \\
\text { factor }\end{array}$ & $\begin{array}{c}\text { Horizontal } \\
\text { inertial force of } \\
\text { crane }\left(\mathrm{m} / \mathrm{s}^{2}\right)\end{array}$ & $\begin{array}{l}\text { Rated loading } \\
(\mathrm{t})\end{array}$ & $\begin{array}{l}\text { Lifting move } \\
\text { load factor }\end{array}$ & $\begin{array}{l}\text { Load } \\
\text { position }\end{array}$ \\
\hline 1 & 9.8 & 15.765 & 1.1 & 0.32 & 50 & 1.14 & $\begin{array}{l}\text { Middle of the } \\
\text { beam }\end{array}$ \\
\hline 2 & 9.8 & 15.765 & 1.1 & 0.32 & 50 & 1.14 & $\begin{array}{l}\text { Left end of } \\
\text { the beam }\end{array}$ \\
\hline 3 & 9.8 & 15.765 & 1.1 & 0.32 & 50 & 1.14 & $\begin{array}{l}\text { Right end of } \\
\text { the beam }\end{array}$ \\
\hline 4 & 9.8 & 15.765 & 1.1 & 0.32 & 50 & 1.14 & $\begin{array}{l}\text { Left } 1 / 4 \text { of the } \\
\text { beam }\end{array}$ \\
\hline 5 & 9.8 & 15.765 & 1.1 & 0.32 & 50 & 1.14 & $\begin{array}{l}\text { Right } 1 / 4 \text { of } \\
\text { the beam }\end{array}$ \\
\hline
\end{tabular}

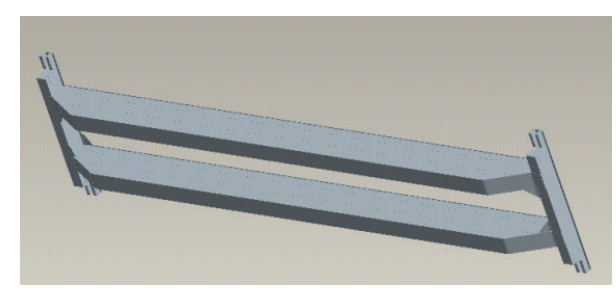

FIgURE 2: Geometric model of double girder crane.

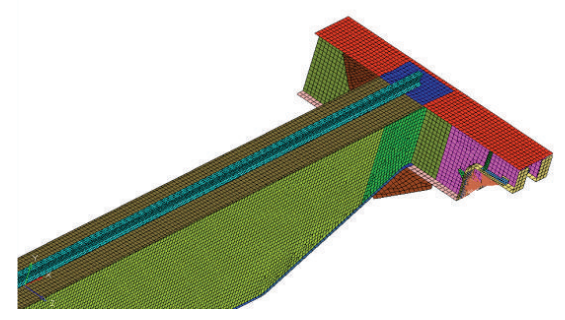

Figure 3: Finite element model.

conditions, and the magnitude of the loadings (L0, L1, L2, L3, and L4) is $322.2485 \mathrm{KN}$. Five work conditions are calculated in finite analysis as in Table 1.

According to the requirements of the crane design in GBT 3811-2008, "crane design" combined with actual usage, requirements for the stiffness of the crane girder are as follows:

$$
f \leq \frac{1}{800} s,
$$

where $f$ is the deflection displacement, $s$ is the span of the crane [12]. follows:

And requirements for the stress of the crane girder are as

(i) material: Q235;

(ii) yield stress $\sigma_{s}: 235 \mathrm{MPa}$;

(iii) allowable stress $[\sigma] \leq 100 \mathrm{MPa}$ defined by engineering design.

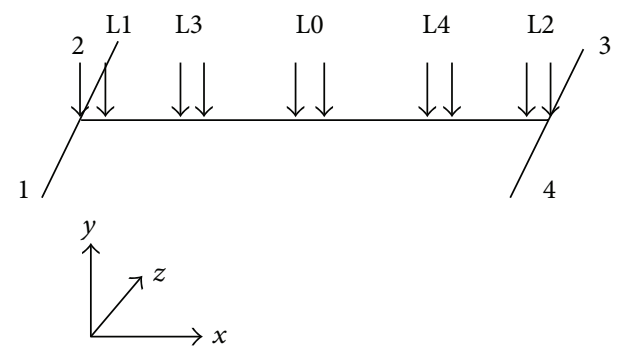

FIGURE 4: Loadings illustration.

After loading on different locations of the main girder, the results of finite element analysis are shown in Figures 5 and 6.

Analyz and compar different conditions of loads to obtain the conclusions that when loading on the middle of the main girder the maximum displacement of $40.3 \mathrm{~mm}$ appears on the middle of the main girder, and the maximum stress of 91.6 MPa occurs on the middle of the main girders. According to the results of FEA, the total mass of the initial model is $18.9 \mathrm{t}$.

\subsection{Structural Optimization of Double Girder Crane}

3.6.1. Shape Optimization. The shape optimal mathematical model is established as follows which takes the minimum volume as objective function, the height and width of the crane as design variables, and the scopes of stress, strain energy, and modal as constraints:

$$
\begin{aligned}
& \text { Min } \quad V^{\prime}(X)=V^{\prime}\left(\text { Height }^{\prime}, \text { Width }^{\prime}\right) \\
& \text { Design variables: } \begin{array}{l}
-5 \leq \text { Height }^{\prime} \leq 20 \\
-5 \leq \text { Width }^{\prime} \leq 20
\end{array} \\
& C_{j}=\frac{1}{2} u_{j}^{T} f_{j} \leq 1.1 \times 10^{7} \mathrm{~J} \quad j=1, \ldots, 5 \\
& \text { s.t. } \quad K u=f \\
& \quad \sigma \leq 100 \mathrm{MPa} \\
& \quad F \geq 3,
\end{aligned}
$$




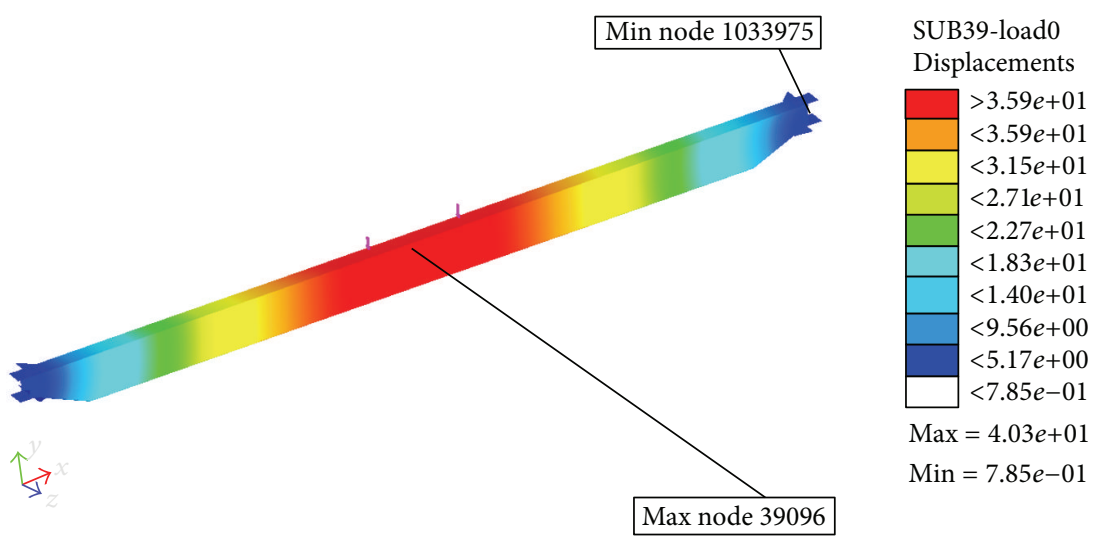

FIGURE 5: Displacement cloud.
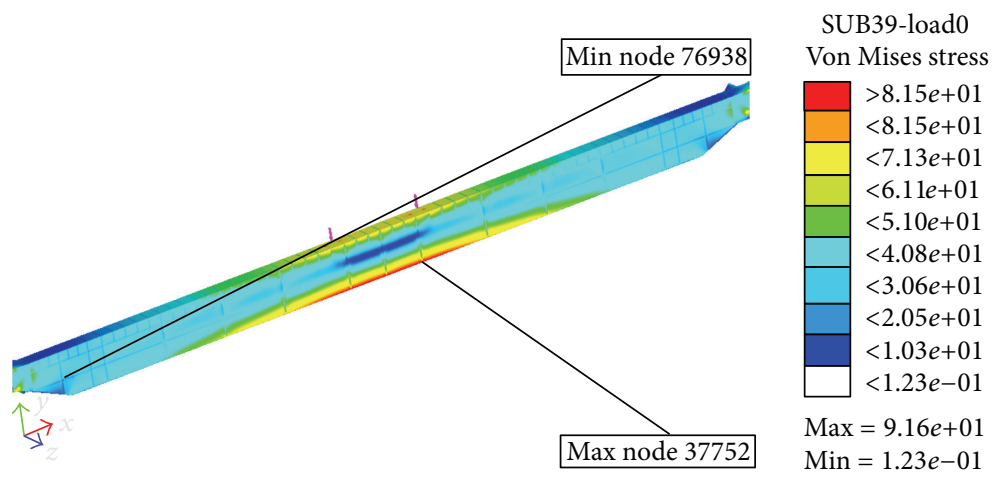

FiguRE 6: Stress cloud.

where $V^{\prime}(X)$ denotes the volume fraction; $C_{j}$ denotes the total strain energy of the crane under the $j$ th load; $K$ denotes the stiffness matrix of the system; $f$ denotes the load; $u$ denotes the node displacement vector under the load $f$; $\sigma$ denotes the stress; $F$ denotes the natural frequency. Objective function $V^{\prime}(X)$, constraint function $C_{j}$, and $\sigma$ can be obtained from structural response of the finite element analysis.

Use OptiStruct Solver to optimize the girder by selecting morph optimization tool; the optimization results of the main girder are shown as follows:

$$
\begin{aligned}
& \text { Volume }=2.27 E+09 \mathrm{~mm}^{3}, \text { Mass }=17.9 \mathrm{t} \\
& \text { Height }^{\prime}=-0.36, \text { Width }^{\prime}=1.2 .
\end{aligned}
$$

After shape optimization:

$$
\begin{aligned}
& \text { Height }=1724 \mathrm{~mm}+0.36 \times 50 \mathrm{~mm}=1742 \mathrm{~mm} \\
& \text { Width }=600 \mathrm{~mm}-1.2 \times 50 \mathrm{~mm}=540 \mathrm{~mm} \\
& \text { Height } / \text { Width }=1724 / 540=3.19 .
\end{aligned}
$$

By analyzing the results of finite element analysis, the structure performance (including strength, stiffness, and modal) after topology optimization meets the requirements of crane design specifications greatly, which are shown in Figures 7 and 8 .

Analyze and compare different conditions of loads to obtain the conclusions that when loading on the middle of the main girder, the maximum displacement of $42.9 \mathrm{~mm}$ appears on the middle of the main girder and the maximum stress of 98.6 MPa occurs on the middle of the main girders. The total mass of the model after shape optimization is $17.9 \mathrm{t}$, which has reduced by $5.3 \%$.

Compare the maximum displacement and maximum stress before and after topology optimization the result is given as in Table 2 .

The analysis results shown in Table 2 show that structure performance of the various plates, some materials of which have been reasonably removed, meets the design requirements as well. Meanwhile, the total mass of structure is $17.9 \mathrm{t}$, which has reduced by $1 \mathrm{t}$.

3.6.2. Size Optimization. Furth optimizing of the structure after shape optimization was carried out in our research. Taking the minimum volume as the objective function, the thicknesses of the plates as the design variables, the scopes of the stress, strain energy, and modal as constraints, the size optimal mathematical model is established as follows:

$$
\begin{array}{ll}
\text { Min } & V(X)=V\left(x_{1}, x_{2}, \ldots, x_{18}\right) \\
\text { S.T. } & C_{j}=\frac{1}{2} u_{j}^{T} f_{j} \leq 1.1 \times 10^{7} J \quad j=1, \ldots, 5
\end{array}
$$



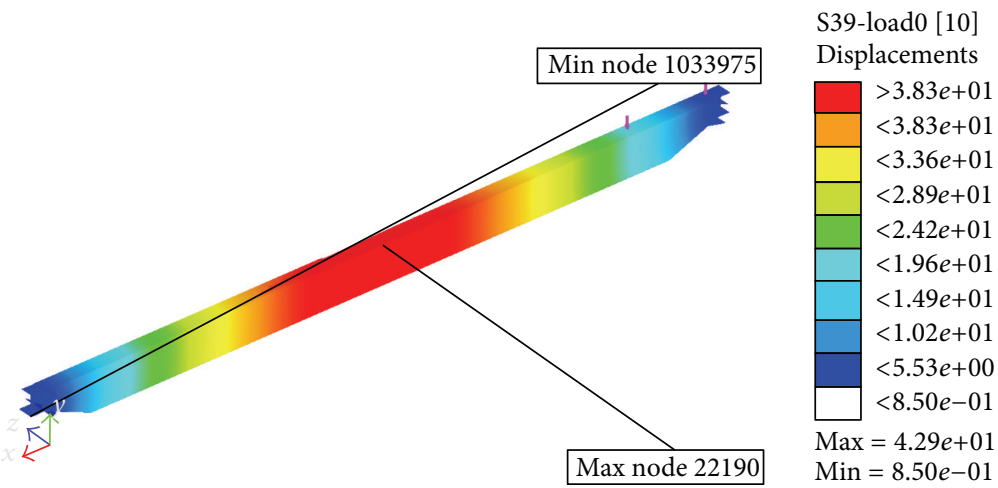

Figure 7: Displacement cloud.

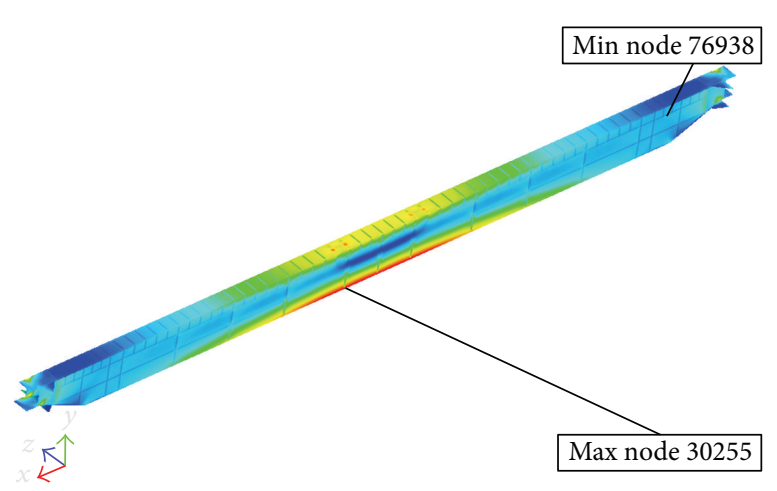

S39-load0 [10]

Von Mises stress

$>8.74 e+01$

$<8.74 e+01$

$<7.65 e+01$

$<6.56 e+01$

$<5.47 e+01$

$<4.38 e+01$

$<3.29 e+01$

$<2.20 e+01$

$<1.11 e+01$

$<1.52 e-01$

$\mathrm{Max}=9.84 e+01$

Min $=1.52 e-01$

FIGURE 8: Stress cloud.

$$
\begin{aligned}
& K u=f \\
& \sigma \leq 100 \mathrm{MPa} \\
& F \geq 3,
\end{aligned}
$$

where $X=x_{1}, x_{2}, \ldots, x_{18}$ denotes the thicknesses of plates, $V(X)$ denotes the total volume of the crane, the rest of variable parameters are denoted as above. Use the OptiStruct Solver to optimize girders by size optimization tool. The optimization results of the thicknesses of the plates are shown in Table 3.

By analyzing the results of size optimization, the structure performance (including strength, stiffness, and modal) after topology optimization meets the requirements of crane design specifications greatly. The results of finite element analysis after size optimization are shown in Figures 9 and 10.

The maximum displacement of $44.1 \mathrm{~mm}$ appears on the middle of the main girder, and the maximum stress of $99 \mathrm{MPa}$ occurs on the end of the main girders. The total mass of the model after size optimization is $17.3 \mathrm{t}$, which has reduced by $8.5 \%$.

The comparison of initial model and final model is shown in Table 4.

From the analysis results shown in Table 4, it can be found easily that the structure performance after shape and size optimization meets the requirements of crane design specifications greatly. Moreover, after size optimization, the total mass of the main girder changes into $17.3 \mathrm{t}$ which has been reduced by $1.6 \mathrm{t}$.

3.6.3. Topology Optimization. Furth optimizing of the structure after shape and size optimization was carried out. The topology optimal mathematical model is established as follows which takes the minimum volume fraction as objective function, the material density of each element as design variables, and the scopes of stress, strain energy, and modal as constraints:

$$
\begin{aligned}
& \operatorname{Min} \quad V^{\prime}(X)=V^{\prime}\left(x_{1}, x_{2}, \ldots, x_{n}\right) \\
& C_{j}=\frac{1}{2} u_{j}^{T} f_{j} \leq 1.1 \times 10^{7} J \quad j=1, \ldots, 5 \\
& \text { s.t. } \quad K u=f \\
& \sigma \leq 100 \mathrm{MPa} \\
& F \geq 3,
\end{aligned}
$$

where $X=x_{1}, x_{2}, \ldots, x_{n}$ denotes the material density of each element are and the rest of variable parameters are denoted as above. 
TABLE 2: Comparison of the stress and displacement.

\begin{tabular}{lcccc}
\hline Load step & \multicolumn{3}{c}{ Before } & After \\
& Stress $(\mathrm{MPa})$ & Displacement $(\mathrm{mm})$ & Stress $(\mathrm{MPa})$ & Displacement $(\mathrm{mm})$ \\
\hline L0 & 91.6 & 40.3 & 98.6 & 42.9 \\
L1/L2 & 80.2 & & 87.2 & \\
L3/L4 & 74.5 & & 74.4 & \\
\hline
\end{tabular}

TABle 3: Comparison of the thicknesses before and after optimization.

\begin{tabular}{lcc}
\hline Main optimal size & Before $(\mathrm{mm})$ & After $(\mathrm{mm})$ \\
\hline Upper plates & 24 & 20.7 \\
Under plates & 24 & 23.4 \\
Inside plates & 6 & 6 \\
Outside plates & 6 & 6 \\
Small ribbed plates & 8 & 9.5 \\
Big ribbed plates & 8 & 5.6 \\
\hline
\end{tabular}

Use OptiStruct Solver to optimize the girder by selecting topology optimization tool; the optimization results of the main girder are shown in Figures 11 and 12.

By analyzing the results of topology optimization, the structure performance (including strength, stiffness and modal) after topology optimization meets the requirements of crane design specifications greatly. The results of finite element analysis after topology optimization are shown in Figures 13 and 14.

Analyze and compare different conditions of loads to obtain the conclusions that when loading on the middle of the main girder, the maximum displacement of $39.9 \mathrm{~mm}$ appears on the middle of the main girder and the maximum stress of $99 \mathrm{MPa}$ occurs on the end of the main girders. The total mass of the model after topology optimization is $15.8 \mathrm{t}$, which has reduced by $16.4 \%$.

Compare the maximum displacement and maximum stress before and after topology optimization; the result is given as in Table 5 .

The analysis results shown in Table 5 show that structure performance of the various plates, some materials of which have been reasonably removed, meets the design requirements as well. Meanwhile, the total mass of structure is $15.8 \mathrm{t}$, which has reduced by $3.1 \mathrm{t}$.

3.7. Overall Stability Analysis of Main Girder. According to the requirements of "the crane design manual" for box section structure, "when aspect ratio (height/width) denoted by $h / b \leqslant 3$ or $3<h / b \leqslant 6 \& 1 / b \leq 95\left(235 / \sigma_{s}\right)$, the lateral buckling stability of the flexural components do not need verify."

In our research, the results are as follows:

before optimization: $h=1724 \mathrm{~mm}, b=600 \mathrm{~mm}, h / b=$ 2.87 , so $h / b \leqslant 3$;

after optimization: $h=1742 \mathrm{~mm}, b=540 \mathrm{~mm}, h / b=$ 3.19 , and $l=31500 \mathrm{~mm}, l / b=58.3, \sigma_{s}=253 \mathrm{MPa}$, so $3<h / b \leqslant 6 \& l / b \leq 95\left(235 / \sigma_{s}\right)$.
Therefore, lateral buckling stability conforms to the design requirements.

\section{System-Level Multidisciplinary Energy-Saving Optimization Design of Bridge Crane}

Energy-saving transmission design is researched by our research group in dynamic simulation and speed regulation of hoisting mechanism as well as optimization and innovation of transmission mechanism scheme reported in the literature $[13,14]$. Thus, self-vibration load factor in Section 3.4 is reduced from 1.14 to 1.11 under VVVF, and the car mass in Section 3.4 is reduced from $15.765 \mathrm{t}$ to $14.4 \mathrm{t}$. Systemlevel multidisciplinary energy-saving optimization design of bridge crane can be further carried out with energysaving transmission design results feedback to energy-saving optimization design of metal structure. By repeating the above modelling and analysis in Section 3, the systemlevel multidisciplinary energy-saving optimization results are shown in Table 6.

\section{Conclusions}

The framework of multidisciplinary energy-saving optimization design of bridge crane is proposed. And the structurelevel optimization design of bridge crane by using finite element analysis technology is discussed in this paper in detail. This research seeks to get more reasonable, lightweight, and energy-saving structure on the basis of insuring the performances of crane and to provide the design reference for bridge crane. The main results of this research can be concluded as follows:

(1) the results of finite element analysis show that the concentrated stress occurs on the middle of main girders under full load;

(2) for the cranes which meet the design requirements, shape optimization is researched. The total mass of the structure after shape optimization changes into $17.9 \mathrm{t} / 17.6 \mathrm{t}$ (optimization design of metal structure/system-level multidisciplinary energy-saving optimization), and it is reduced by $1 \mathrm{t} / 1.3 \mathrm{t}$ compared with the initial model;

(3) size optimization is researched after shape optimization. The total mass of the structure after size optimization changes into $17.3 \mathrm{t} / 16.7 \mathrm{t}$, and it is reduced by $1.6 \mathrm{t} / 2.2 \mathrm{t}$; 
TABLE 4: Comparing the stress and displacement.

\begin{tabular}{lcccc}
\hline \multirow{2}{*}{ Load step } & \multicolumn{2}{c}{ Initial model } & \multicolumn{2}{c}{ Final model } \\
& Stress $(\mathrm{MPa})$ & Displacement $(\mathrm{mm})$ & Stress $(\mathrm{MPa})$ & 99 \\
L0 & 91.6 & 40.3 & 84.4 & \\
L1/L2 & 80.2 & & 88.3 & \\
L3/L4 & 74.5 & & 88.1 \\
\hline
\end{tabular}

TABLE 5: Comparison of the stress and displacement.

\begin{tabular}{lcccc}
\hline Load step & \multicolumn{3}{c}{ Before } & After \\
& Stress (MPa) & Displacement $(\mathrm{mm})$ & Stress (MPa) & Displacement (mm) \\
\hline L0 & 91.6 & 40.3 & 97.6 & 43.9 \\
L1/L2 & 80.2 & & 90 & \\
L3/L4 & 74.5 & & 108 & \\
\hline
\end{tabular}

TABLE 6: System-level multidisciplinary energy-saving optimization results.

\begin{tabular}{lcc}
\hline Optimization method & Mass after optimization $(\mathrm{t})$ & Percentage decrease \\
\hline & 18.9 & $6.88 \%$ \\
Shape optimization & 17.6 & $11.64 \%$ \\
Size optimization & 16.7 & $16.40 \%$ \\
Topology & 15.8 & 160 \\
optimization & & \\
\hline
\end{tabular}

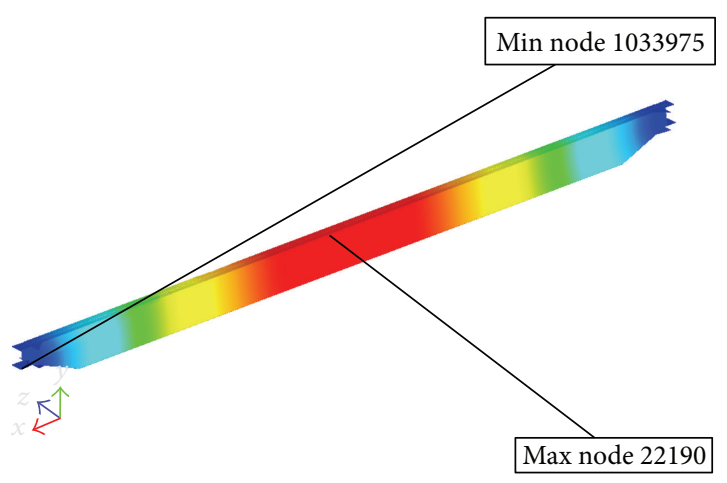

FIGURE 9: Displacement cloud.

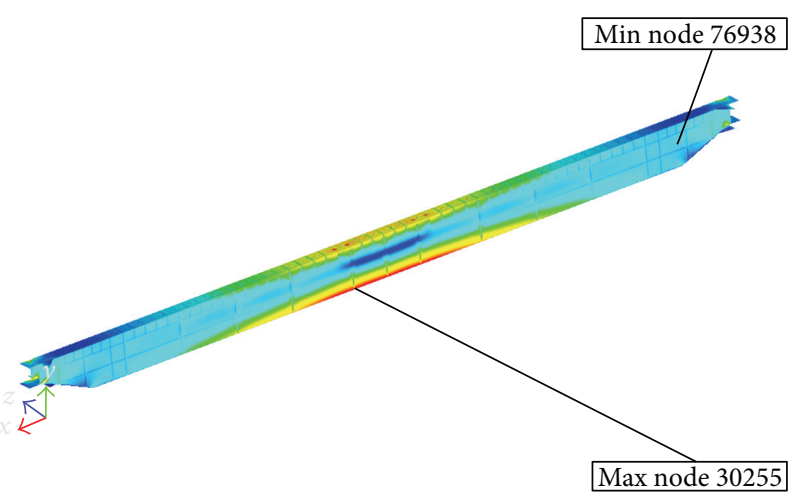

FIgURE 10: Stress cloud.
S39-load0 [3]

Displacements

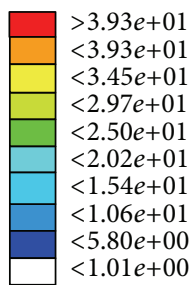

$\operatorname{Max}=4.41 e+01$

Min $=1.01 e+00$ 


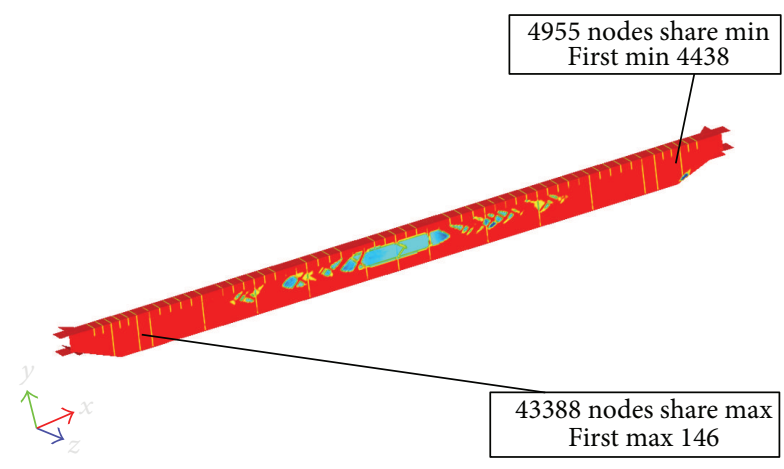

FIGURE 11: Density graph of the side plate.

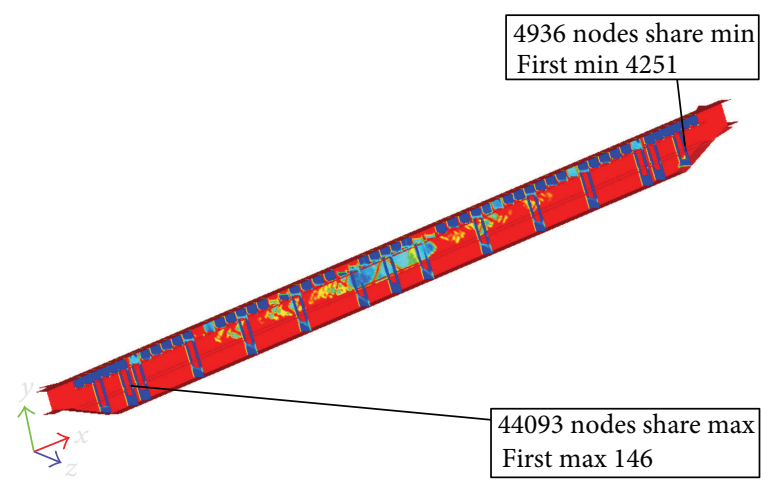

FIGURE 12: Density graph of the belly board.

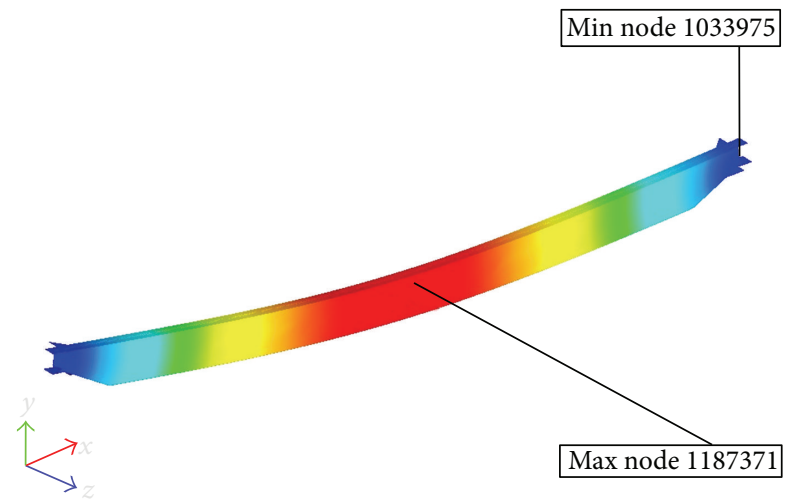

FIGURE 13: Displacement cloud.

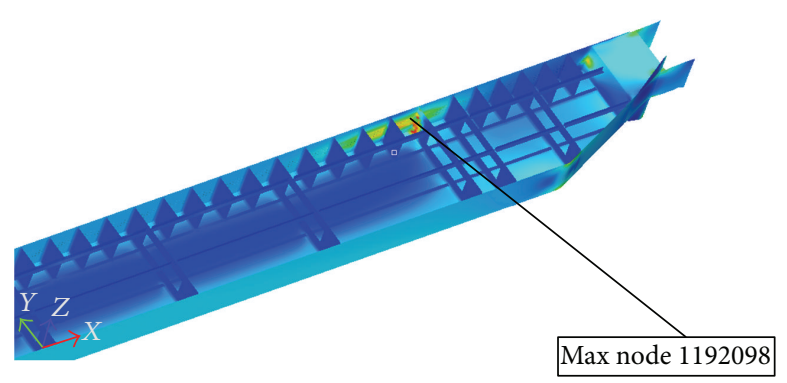

Figure 14: Stress cloud.
Design [32]

Element density $>8.90 e-01$ $<8.90 e-01$ $<7.80 e-01$ $<6.70 e-01$ $<5.60 e-01$ $<5.60 e-01$ $<4.50 e-01$
$<3.40 e-01$ $<2.30 e-01$ $<1.20 e-01$ $<1.00 e-02$

$\operatorname{Max}=1.00 e+00$ Min $=1.00 e-02$

Design [32] Element density

$\square>8.90 e-01$ $<8.90 e-01$

$<7.80 e-01$ $<6.70 e-01$ $<5.60 e-01$ $<4.50 e-01$

$<3.40 e-01$

$<2.30 e-01$

$<1.20 e-01$

$<1.00 e-02$

$\operatorname{Max}=1.00 e+00$

$\mathrm{Min}=1.00 e-02$

S39-load0 [37] Displacements

$>3.91 e+01$
$<3.91 e+01$ $<3.91 e+01$ $<3.43 e+01$ $<2.48 e+01$ $<2.00 e+01$ $<2.00 e+01$ $<1.05 e+01$ $<5.73 e+00$ $<9.69 e-0$ $\operatorname{Max}=4.39 e+01$ $\operatorname{Min}=9.69 e-01$ 
(4) topology optimization based on density methodology is used after shape and size optimization. The total mass of the structure after topology optimization changes into $15.8 \mathrm{t} / 15.8 \mathrm{t}$, and it is reduced by $3.1 \mathrm{t} / 3.1 \mathrm{t}$ compared with the initial model;

(5) multidisciplinary optimization design by means of finite element analysis and dynamic simulation not only can assure stiffness, strength, and other performances requirements of the crane but also can greatly reduce the use of materials by lightweight design.

\section{Acknowledgments}

This work was financially supported by National Foundation of General Administration of Quality Supervision and Inspection (2012QK178), program of Science Foundation of General Administration of Quality Supervision and Inspection of Jiangsu Province (KJ103708), and "excellence planszijin star" Foundation of Nanjing University of Science. The support is gratefully acknowledged.

\section{References}

[1] N. Zhaoyang, R. Yongxin, R. Chengao et al., "ANSYS application in design of the main beam of crane," Machinery for Lifting and Transportation, vol. 5, pp. 31-33, 2008.

[2] M. Styles, P. Compston, and S. Kalyanasundaram, "Finite element modelling of core thickness effects in aluminium foam/composite sandwich structures under flexural loading," Composite Structures, vol. 86, no. 1-3, pp. 227-232, 2008.

[3] C. Nucera and F. L. Scalea, "Higher-harmonic generation analysis in complex waveguides via a nonlinear semianalytical finite element algorithm," Mathematical Problems in Engineering, vol. 2012, Article ID 365630, 16 pages, 2012.

[4] L. Kwasniewski, H. Li, J. Wekezer, and J. Malachowski, "Finite element analysis of vehicle-bridge interaction," Finite Elements in Analysis and Design, vol. 42, no. 11, pp. 950-959, 2006.

[5] Y. Li, Y. Pan, J. Zheng et al., "Finite element analysis with iterated multiscale analysis for mechanical parameters of composite materials with multiscale random grains," Mathematical Problems in Engineering, vol. 2011, Article ID 585624, 19 pages, 2011.

[6] D. Qin, Y. Wang, X. Zhu, J. Chen, and Z. Liu, "Optimized design of the main beam of crane based on MSC1Patran/Nastran," Machinery for Lifting and Transportation, vol. 7, pp. 24-26, 2007.

[7] D. Hongguang, B. Tianxiang, S. Yanzhong, and Y. Sikun, "The optimum design of single girder bridge-crane based on FEM," Steel Construction, vol. 2, pp. 46-48, 2009.

[8] L. Hui, Y. Haipeng, and L. Huixin, "The malfunction about the bridge crane girder based on FEM," Construction Machinery, vol. 2, pp. 67-69, 2007.

[9] W. Fumian, "Discussion about the static stiffness design of the bridge crane and the related problems," Machinery for Lifting and Transportation, vol. 12, pp. 42-44, 2009.

[10] Z. Zhang, "The application of ANSYS into optimizing design of main beam in joist portal crane," Machinery Technology and Management on Construction, vol. 8, pp. 91-93, 2009.

[11] Y. Menglin, Q. Dongchen, L. Zhuli, and W. Y. Jia, "Research on structure optimization design of bridge crane box beam," Design and Research, vol. 4, pp. 23-24, 2008.
[12] GBT3811-2008, Crane design standard.

[13] L. Shuishui, F. Yuanxun, and B. Tingchun, "Introduction for new hoisting mechanism of a crane," Machinery Design \& Manufacture, no. 5, pp. 275-276, 2012.

[14] F. Yuanxun, B. Tingchun, and L. Shuishui, "Co-simulating on lifting dynamic load of bridge crane based on ADAMS and MATLAB," Heavy Machinery, no. 5, pp. 30-32, 2011. 


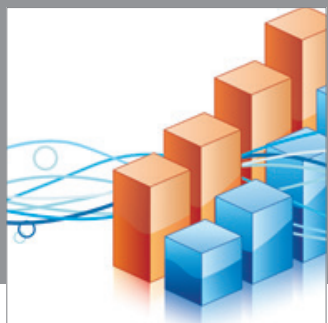

Advances in

Operations Research

mansans

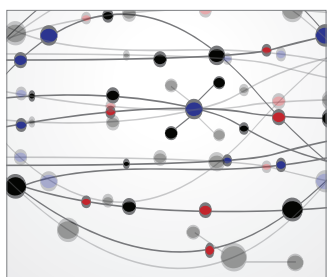

The Scientific World Journal
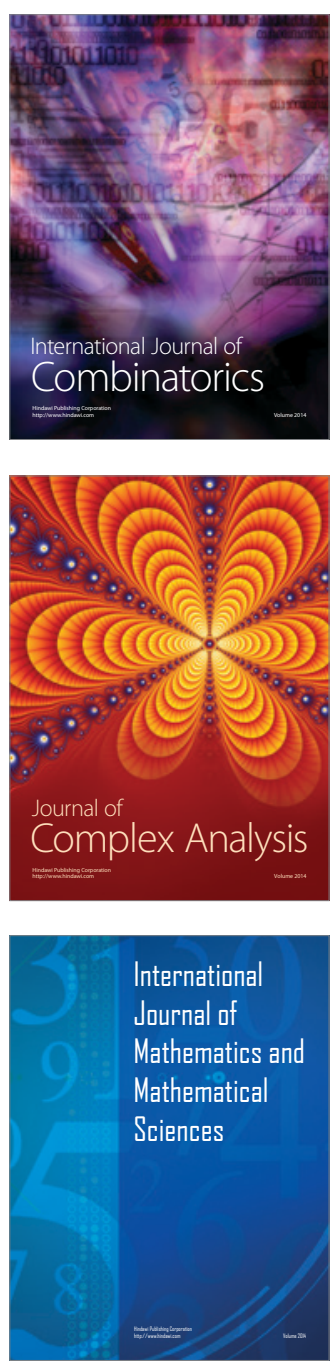
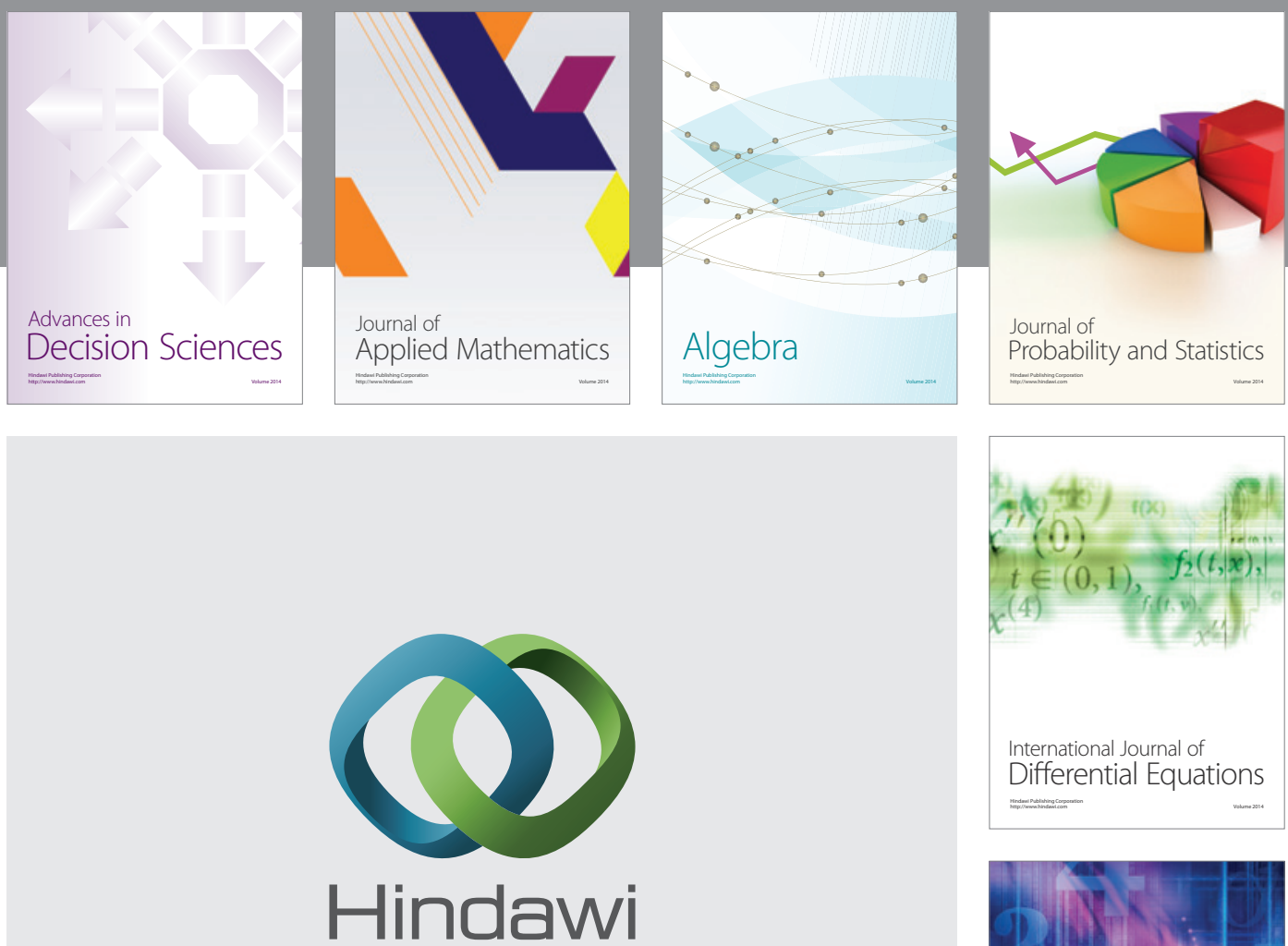

Submit your manuscripts at http://www.hindawi.com
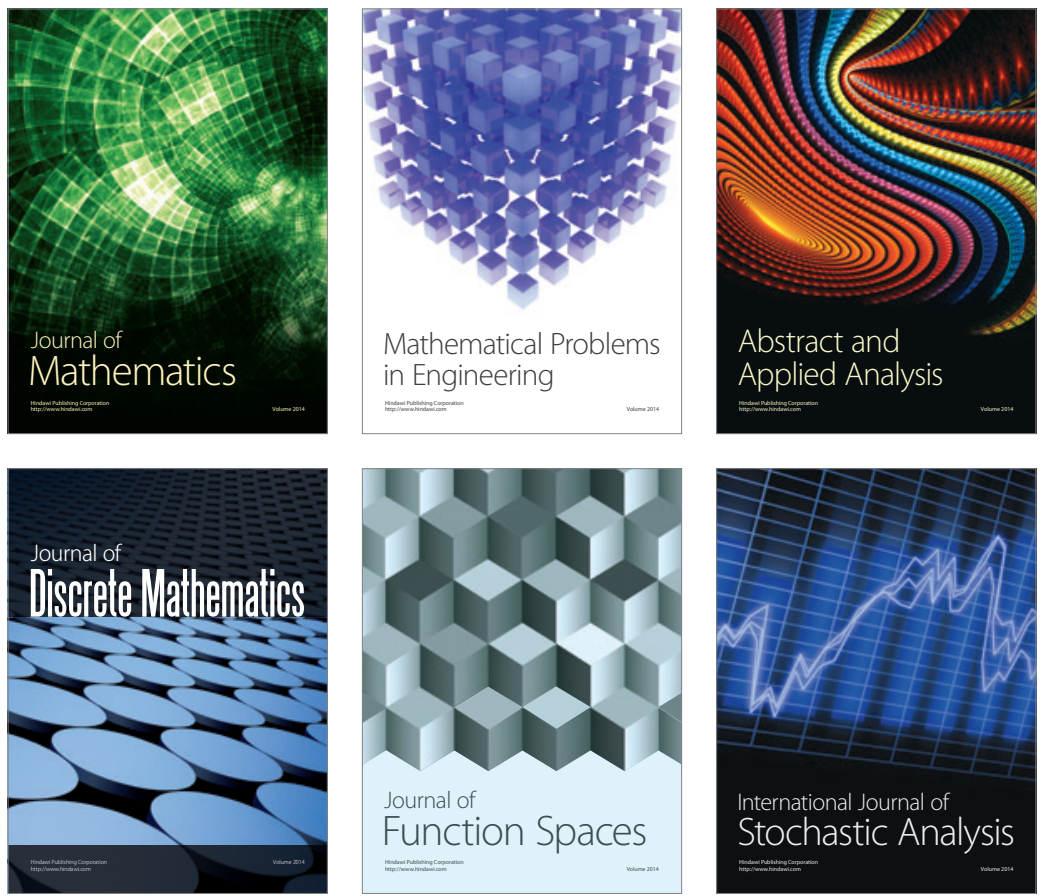

Journal of

Function Spaces

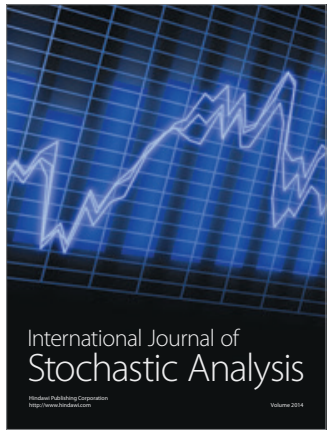

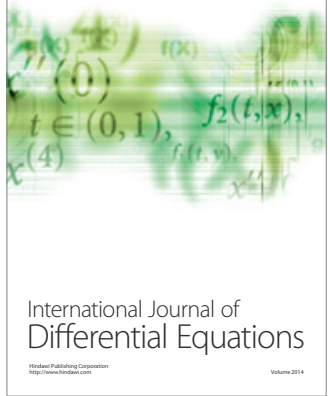
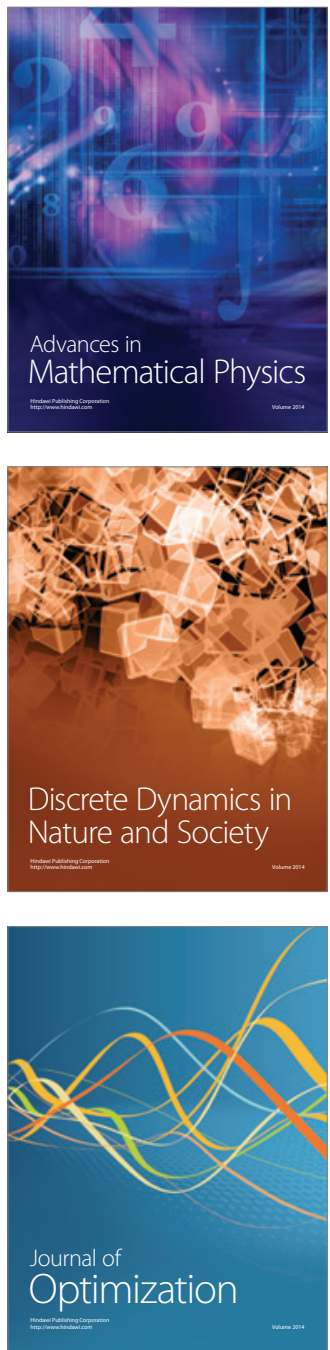